Journal of Management

Vol. 43 No. 5, May 2017 1359-1387

DOI: $10.1177 / 0149206314552452$

(C) The Author(s) 2014

Reprints and permissions:

sagepub.com/journalsPermissions.nav

\title{
Sell-Offs and Firm Performance: A Matter of Experience?
}

\author{
Matthias Brauer \\ University of Mannheim \\ Jan Mammen \\ University of Erlangen-Nuremberg \\ Johannes Luger \\ University of Geneva
}

\begin{abstract}
Drawing on organizational learning theory, this article examines the moderating influences of different forms of internal and external sell-off experience on the relationship between firm selloff activity and subsequent firm accounting performance. The results from a longitudinal analysis of sell-off activity by 293 European companies over a 15-year period (1995-2009) are consistent with basic predictions from learning theory, suggesting a positive moderating influence of a firm's general sell-off experience. Yet, by distinguishing between multiple forms of learning (i.e., experiential, superstitious, interfirm, and vicarious learning), we further argue and find that the composition of a firm's general sell-off experience is of substantial importance. Specifically, we find that learning benefits result from the repeated sale of related assets, whereas high levels of experience heterogeneity negatively affect the relationship between firm sell-off activity and subsequent firm performance. Furthermore, external sell-off experience by advisors and by industry peers is found to positively influence the divestiture-firm performance linkage. Collectively, these findings contribute to organizational learning theory and extend prior research on divestiture performance.
\end{abstract}

Keywords: organizational learning; restructuring (divestitures); organizational development

\footnotetext{
Acknowledgments: This article was accepted under the editorship of Deborah E. Rupp. We are grateful to associate editor Patrick Wright and our two anonymous reviewers for their constructive comments and guidance. We also particularly thank Donald Bergh, Emilie Feldman, and Tomi Laamanen for their helpful comments on earlier versions of this article.
}

Corresponding author: Matthias Brauer, University of Mannheim, L4,1, Mannheim 68131, Germany.

E-mail:mbrauer@mail.uni-mannheim.de 


\section{Introduction}

Divestitures, which are understood as a firm's adjustments of its ownership and business portfolio structure via sell-offs, spin-offs, equity carve-outs, or split-ups (e.g., Mulherin \& Boone, 2000), have increasingly been recognized as an important strategic activity in both strategic management research and business practice (Brauer, 2006; Lee \& Madhavan, 2010; Mankins, Harding, \& Weddigen, 2008). Extant empirical research on divestitures indicates that, on average, divestitures improve a firm's accounting performance (e.g., Hoskisson \& Johnson, 1992; Markides, 1995) and are positively received by capital markets (Lee \& Madhavan, 2010). Drawing on transaction cost economics and agency theory, the positive performance implications of divestitures and the positive reception by capital markets have been argued to originate primarily from the reduction of operational ("negative synergies") and managerial inefficiencies (Afshar, Taffler, \& Sudarsanam, 1992; Harrigan, 1981, 1985; John \& Ofek, 1995).

Despite the importance of divestitures to firm performance, we have only a very basic understanding of whether and how firms can learn from previous divestitures and, hence, how they can improve the success of subsequent divestiture activity. By applying an organizational learning perspective to better understand the performance implications of firm divestiture activity, we extend the theoretical repertoire of extant divestiture research that has mainly relied on agency theory, transaction cost economics, or portfolio theory (Brauer, 2006). Moreover, the use of a learning perspective departs from the view of divestitures as "one-off activities" (Mankins et al., 2008: 99). Furthermore, by applying a learning perspective, we build on recent work in divestiture research. Bergh and Lim (2008) were the first to provide empirical evidence that a firm's general divestiture experience, defined as a firm's engagement in prior divestitures, leads to improved financial performance. But while Bergh and Lim mainly relied on the theoretical notions of absorptive capacity and organizational improvisation, we incorporate additional insights from learning theory by distinguishing between multiple forms of learning (i.e., experiential, superstitious, interfirm, and vicarious learning) (e.g., Haunschild \& Miner, 1997; Levitt \& March, 1988). Building on the notions of experiential, interfirm, and vicarious learning, we argue that managers are generally able to benefit from "learning by doing," "learning by transferring," or "learning by observing" when repeatedly performing or being involved in the key tasks along the different stages of the sell-off process (i.e., asset identification, asset transaction, asset separation, and asset reallocation). At the same time, we acknowledge the potential for superstitious learning when managers transfer insights from only seemingly similar deal contexts.

Another important addition from an organization learning perspective, which is introduced in the current study, is the decomposition of general experience into internal and external experience. The distinction between internal and external experience is theoretically meaningful as the idiosyncrasy and complexity of sell-offs may require both forms of experience. On the one side, as sell-offs are highly idiosyncratic activities (Bergh \& Lim, 2008), firms need to learn their own lessons and may not simply copy the practices adopted by others. On the other side, especially during situations of high complexity and uncertainty, scholars have indicated that firms shift their attention to external sources of knowledge (Mezias \& Lant, 1994). When facing uncertainty, firms seek external advice, trying to orient toward legitimized "best practices" (Haunschild \& Miner, 1997; Kim \& Miner, 2007).

With regard to internal experience, we argue that whether firms build up their general experience base from divestitures undertaken in very different industries ("experience 
heterogeneity") and whether firms build up experience from divesting highly related units/ assets ("experience relatedness") influence the effectiveness of learning transfers. In particular, we claim that experience heterogeneity fosters superstitious learning leading to inferior outcomes. In contrast, experience relatedness is argued to enable a more effective exchange of experience due to greater management attention and familiarity with related assets. With regard to external experience, we examine whether firms' reliance on external advisors' divestiture experience and whether the divestiture experience by industry peers moderate the relationship between sell-off activity and firm performance. While in the former case firms may benefit from external advisors' interfirm knowledge transfer, in the latter case firms potentially benefit from vicarious learning, which, among others, helps avoid costly mistakes in the deal-making process.

To examine these internal and external experience effects in the context of divestitures, we analyze the sell-off activity of 293 European companies over a 15-year period (1995-2009). We focus on sell-offs because it is the most common mode of divestiture (Brauer, 2006). In doing so, our article contributes to divestiture research and organizational learning theory. Utilizing a learning perspective, we extend the theoretical repertoire to explain sell-offs' positive performance outcomes, and highlight how distinct learning mechanisms can amplify or dampen the performance effects of sell-offs. Moreover, through studying learning effects in sell-offs as a type of contractionary strategic decision, we explore differences to learning effects occurring in expansionary strategic decisions (e.g., acquisitions, alliances). Furthermore, this study contributes to organizational learning theory by decomposing general sell-off experience, by distinguishing between internal and external forms of experience, and by extending extant insights on the sources and effects of superstitious learning.

\section{Background and Hypotheses}

\section{Sell-Offs and Firm Financial Performance}

Previous empirical research has generally found a positive relationship between sell-offs and subsequent accounting performance (e.g., Bergh, 1998; Hoskisson \& Johnson, 1992; Markides, 1995). To explain the sources of sell-off gains, scholars have developed and tested several hypotheses. The most popular explanation in the literature is that gains result from improved corporate efficiency after sell-offs (Brauer, 2006). Specifically, it has been argued that sell-offs reduce operational and managerial inefficiencies (Harrigan, 1981, 1985; Hoskisson, Johnson, \& Moesel, 1994; John \& Ofek, 1995; Markides, 1992; Markides \& Singh, 1997). Markides, for example, argued that large firms face "managerial diseconomies of scale" (1992: 399) and asset sell-offs may be a way to reduce these inefficiencies. In finance research, scholars have argued that managerial efficiency is improved after sell-offs by limiting the influence costs generated by lower level management (Schipper \& Smith, 1983). Concerning operational inefficiencies, most scholars argue that sell-offs primarily improve a firm's efficiency with respect to its financial resource allocation by avoiding crosssubsidies and eliminating negative synergies (Afshar et al., 1992; Schipper \& Smith, 1983). The underlying argument is that beyond a certain level of diversification, a firm is unable to achieve more efficient allocation of capital resources between units and monitor the efficiency of units more effectively than the stock market could if each unit were an independent entity (Brauer, 2006). Both arguments are closely related to a firm's optimal level of diversification, suggesting that widely diversified firms use sell-offs to reduce complexity and, 
hence, improve the efficiency of their remaining resources (Bergh, 1997). Together, this leads to our baseline hypothesis:

Baseline hypothesis: Sell-off activity is positively associated with a firm's accounting performance.

\section{Learning Opportunities in the Sell-Off Process}

While sell-offs have generally been found to be positively associated with firm performance, the execution of sell-offs has been described as a difficult multistage process (Brauer, 2009). A synthesis of prior literature suggests four major stages in the sell-off process: asset identification, asset transaction, asset separation, and asset reallocation. The first two stages include all tasks up to the closing and signing of the deal, while the latter stages comprise the tasks after signing of the deal.

The first stage, asset identification, describes the selection of assets that are to be sold. Among others, scholars predicted financially poor performing units (e.g., Hitt, Hoskisson, Johnson, \& Moesel, 1996), unrelated units with missing interdependencies (e.g., Duhaime \& Grant, 1984), or relatively small units (Shimizu \& Hitt, 2005) to have a higher probability of being sold. When it comes to asset deselection, the managerial challenge is to identify the root cause(s) for the asset's inferior performance. In addition, it becomes challenging to anticipate the negative effects asset deselection may have on remaining assets. By repeatedly engaging in asset deselection processes by themselves, with the help of advisors, or by observing industry peers, managers are likely to generate stronger capabilities in identifying the "right" assets, leading to stronger increases in firm accounting performance from subsequent sell-offs.

The second stage, asset transaction, includes all managerial tasks up to the closing and signing of the asset sale. It comprises the search for and selection of potential buyers (Datta, Iskandar-Datta, \& Raman, 2003), the valuation of the asset (Krishnaswami \& Subramaniam, 1999), and finally the actual contract negotiations (Walsh, 1989). By engaging in multiple deals, managers are able to develop a much better understanding of the suitable buyer universe. Among others, managers learn to opt for the suitable contact approach (private sale vs. limited/open auctioning approach) dependent on their assessment of the buyer universe and its composition (strategic vs. financial buyers). Especially during the asset transaction stage, firms may also benefit from the experience of external advisors who are commonly even more familiar with the standard valuation ranges, average industry multiples, or the financial and legal processing of a focal sell-off. Together, these learning effects positively influence sell-off and firm performance.

The third stage, asset separation, involves the challenging processes of unbundling and detaching resources (Brauer, 2009; Burgelman, 1994). Unbundling refers to the division of shared resources (e.g., patents) among divested and retained units and is regarded as especially difficult since it involves multiple managerial levels. Moreover, asset separation should be conducted in a way that ensures that the parent and the divested unit are able to operate as freestanding firms (Rosenbluth, 2002). If managers are inexperienced regarding the process of resource disentanglement, this can substantially hurt the parent firm's resource base, and lead to deteriorating firm performance despite a generally positive effect from the sell-off itself. 
Detaching is defined as the migration of external customer relationships and the loosening and final separation of internal customer relationships. For internal customers (i.e., other units that were supplied by the sold-off unit), managers need to learn how to effectively manage the transition process to avoid disruptions for the remaining units which could negatively affect overall firm accounting performance. For external customers, managers need to learn to manage the detachment process with great care to limit customer attrition, which would otherwise also negatively impact the firm's overall accounting performance (Brauer, 2009). Among others, this involves a refined communication process toward external customers.

The final stage of the sell-off process, asset reallocation, deals with the reinvestment of the existing freed-up resources as well as the deployment of new additional (mainly financial) resources which are received from the sale. Selling firms have been argued to benefit from "increased efficiency arising from a better allocation of management time and other resources in a more focused firm" (John \& Ofek, 1995: 108). As outlined by Burgelman (1994), especially middle managers may play a crucial role in the reallocation process. By engaging in multiple sell-offs, managers are likely to refine their expertise to timely and effectively redeploy resources after the transaction. Likewise, as firms observe prior asset reallocation decisions by their industry peers, they learn about the industry's reorientation to a different resource base, therefore being more efficient in reinvesting their freed-up resources.

In summary, the sell-off process can be conceived as a multistage process that involves several challenging managerial tasks. As managers engage in repeated sell-offs, however, they might learn to execute these tasks more effectively, leading to improved sell-off and firm outcomes. In the following paragraphs, we discuss more specifically based on organizational learning theory how distinct forms of learning (i.e., experiential, superstitious, interfirm, and vicarious learning) may influence task performance along the sell-off process.

\section{Experiential Learning}

If sell-offs are thought to improve a firm's accounting performance by eliminating operational and managerial inefficiencies (Harrigan, 1981, 1985; John \& Ofek, 1995; Markides, 1992), the question then becomes how firms become more effective in identifying and then eliminating operational and managerial inefficiencies despite the complexities of the sell-off process. Learning theory suggests that decision makers may manage to do so by engaging in what has been termed "autonomous learning" (Dutton \& Thomas, 1984), "first-order learning" (Adler \& Clark, 1991), or "learning by doing" (Zollo \& Winter, 2002). This implies that learning is generated by knowledge acquired from the repeated actions of organizational members (Arthur \& Huntley, 2005; Berman, Down, \& Hill, 2002; Zollo \& Winter, 2002).

For sell-offs, this means that by repeatedly undertaking the key tasks of identifying selloff targets, valuing them, negotiating contract conditions, unbundling and detaching resources, and finally efficiently reallocating resources, managers will learn how to improve individual task performance, which, in the end, helps generate more positive sell-off outcomes. Overall, through the process of "learning by doing," managers are able to develop effective task procedures, to avoid or change malfunctioning ones, and, hence, to refine the overall sell-off process with each additional deal completion.

A positive moderating effect is further likely to originate from the fact that the extent of general cumulative sell-off experience influences managers' and employees' perceptions of 
the sell-off event. When firms have engaged in multiple sell-offs, corporate-level managers and employees become accustomed to such situations, and grow more confident in managing and communicating them. Given that sell-offs are often accompanied by considerable uncertainty and are usually perceived as a threat, learning reduces managers' perceptions of stress and anxiety (Lawler \& Hall, 1970; Parasuraman \& Alutto, 1981). For example, Gopinath and Becker (2000) indicate that communication directly affects employees' sense of procedural justice and, in turn, raises their commitment. Greater commitment has been found to positively influence employees' job performance and working efficiency (Becker, Billings, Eveleth, \& Gilbert, 1996), leading to more positive firm-level accounting-based performance.

In addition, Brauer (2009) highlights the need to manage communication toward customers, especially if these customers are also customers of retained units. By learning how to effectively communicate the rationale for sell-offs to customers, managers are likely to limit customer attrition which would negatively impact the firm's overall accounting performance.

Taken together, repeated involvement in sell-off processes is thus likely to enhance individual task performance across the different substages of the sell-off process and also to reduce anxiety of managers and employees leading to better learning effects (Winnicott, 1962, 1980). Collectively, this implies a positive moderating influence of the extent of general sell-off experience on the relationship between sell-offs and firm performance.

Hypothesis 1: The extent of general sell-off experience positively moderates the relationship between sell-offs and firm performance.

\section{Superstitious Learning}

The aforementioned process of "first-order learning" builds on original learning curve literature, which proposes that cumulative experience generates efficiency improvements in terms of the cost of the units produced (Yelle, 1979). More recent studies investigating experiential learning effects in more complex settings such as acquisitions (e.g., Haleblian \& Finkelstein, 1999; Hayward, 2002) or alliances (e.g., Anand \& Khanna, 2000), however, have qualified this earlier finding. For experiential learning to work, decision makers need to discover and understand the "causal relationships between the decisions or actions taken and the performance outcomes obtained" (Zollo \& Winter, 2002: 348). We propose that the managerial task of discovering and understanding the causal relationships in the sell-off process becomes increasingly complex if a firm conducts sell-offs in quite different types of industries while becoming less complex if a firm divests assets that are related to the firm's core business. We thus argue that the composition of a firm's cumulative experience, in terms of the heterogeneity of prior experience and the relatedness of previous transactions to the firm's core business, has a substantial influence on whether previous experience is "a good or a bad teacher" (March, 2010: 101).

Experience heterogeneity. The reversal of overdiversification has been argued and found to be a major determinant for firm sell-off activity (Brauer, 2006; Hoskisson \& Hitt, 1994). Dediversification implies that multibusiness firms engage in divestitures from multiple industries. When selling assets from multiple different industries (i.e., experience 
heterogeneity), effective learning seems to be particularly challenging for at least two major reasons: First, experience heterogeneity interferes with managers' ability to build and maintain in-depth expertise in each of the firm's industries. When engaging in sell-offs from multiple different industries, managers will not have developed a refined understanding of the relative importance of sell-offs' substages and will not have accumulated sufficient knowledge on how to increase task performance in these substages. According to previous studies, however, this knowledge is critical for understanding the performance outcomes of sell-offs. For instance, studies have indicated that the stage of asset separation is particularly crucial in high-technology industries involving complex decoupling processes with respect to IT infrastructure and the patent portfolio (Brauer, 2009). In contrast, when assets in low-technology industries are sold, the stage of asset reallocation in terms of the streamlining of operational processes becomes particularly salient for realizing efficiency improvements. Second, experiential learning effects are also likely to be less pronounced when selling assets from multiple industries since managers are less able to draw on established networks to market the assets (Holmqvist, 2004). While it can be expected that managers can leverage the expertise of the same type of networks and contacts when divesting assets in similar industries, the task of selling off assets from very diverse industries requires managers to tap into new networks.

However, the issue is not simply that the sale of assets from different industries makes experiential learning more challenging. In the absence of deep knowledge, the misspecification of connections between actions and outcomes becomes more likely, leading to a greater threat of negative experience transfer. By drawing on a heterogeneous experience base, managers are much more prone to misapply prior experience to current deal contexts that are only superficially similar but structurally different. Levitt and March (1988) termed this "superstitious learning," suggesting that in the context of complex strategic decisions, such as the decision to sell assets from multiple different industries, firms may poorly infer causal linkages between actions and outcomes, leading to inferior decision outcomes. While in alliances or acquisitions superstitious learning has been argued to mainly result from overconfidence (Heimeriks, 2010; Zollo, 2009), superstitious learning associated with sell-offs across industries is more likely to result from oversimplification and the fact that the required knowledge sharing across divisions increases the likelihood that inferences shared are obscure and incomplete (Schwenk, 1984). Especially when exposed to ambiguous and threatening contexts, firms have been found to "oversimplify a complex construct" (Barkema, Shenkar, Vermeulen, \& Bell, 1997: 434), and to come up with too "broad judgments based on past (dissimilar) experiences that create new (false) rules-of-thumb" (Lyles, 1994: 462; Van de Ven and Lin, 1989). The application of false rules of thumb can take different forms in selloffs. For instance, managers may falsely reapply firm and transaction multiples and negotiation practices across sell-offs from distinct industry backgrounds. Both tasks, however, have been described as highly idiosyncratic, that is, valuation metrics or contract terms need to be tailored to the specific asset sold (Barth \& Clinch, 1998). Given large extents of experience heterogeneity, the risk of applying false rules of thumb to current deal activity also seems particularly great since knowledge accumulation requires interaction and communication across divisions. By definition, this means the involvement of a greater number of managers, which, in turn, has been argued to affect the extent of superstitious learning (Lyles, 1994; Van de Ven $\&$ Lin, 1989). This is because not being acquainted with industry specifics means that managers about to complete ongoing transactions are left with half histories. These managers must make up their own endings and meanings to the stories about the events reported by 
other managers from other divisions. Not having the full picture makes it even more difficult to detect erroneous experience transfer.

Finally, substantial levels of experience heterogeneity are also likely to exert a negative influence on the relationship between subsequent sell-offs and firm performance because managers and employees experience greater confusion regarding which insights from past transactions may be readily transferable to subsequent transactions (French \& Caplan, 1973). As Staw, Sandelands, and Dutton (1981) noted, this confusion and anxiety generated by experience heterogeneity induces psychological stress and, thereby, constrains learning. In contrast, drawing on experience accumulated during sell-offs from similar industries may increase managers' and employees' confidence and thus reduce their levels of stress and anxiety enabling effective learning.

In summary, a high level of experience heterogeneity is likely to negatively influence the relationship between a firm's subsequent sell-off activity and firm performance because of greater difficulty to build deep knowledge, greater risk of erroneous learning, and heightened levels of stress and anxiety.

Hypothesis 2: The level of experience heterogeneity negatively moderates the relationship between sell-offs and firm performance.

Experience relatedness. Learning curve theory proposes that organizational learning is positively influenced by the extent of accumulated experience. The above hypothesis on experience heterogeneity, however, further suggested that learning effectiveness is also dependent on the composition of previous experience, which, in the specific case of selloffs, may consist of highly similar or highly dissimilar transactions. In the latter case, this increases the risk of erroneous learning leading to less positive outcomes.

Next, we consider that a firm's ability to learn from previous transactions may also depend on how well the parent firm actually understands the sold unit(s) or asset(s). Specifically, a parent firm is expected to hold more profound knowledge about value creation opportunities for units and assets that are closely related to the parent firm's core business (Campbell, Goold, \& Alexander, 1995). Thus, in line with learning curve theory and the notion of absorptive capacity, which suggest that search and learning are guided and facilitated by the existing knowledge base, we expect firms to particularly benefit from learning when repeatedly selling related units. This is for three main reasons. First, related assets are well understood by the parent firm and receive above average managerial attention (Bergh, 1995). Given a parent firm's better understanding of the nature of the assets and the operational processes involving related assets, experience gains are likely to enhance task performance across the substages of the sell-off process to a significant extent. For instance in the asset transaction stage, the better understanding of related assets helps with defining and standardizing key valuation parameters (e.g., the growth rate in discounted cash-flow analysis). Also, the better understanding of operational processes involving related assets makes it easier for managers to optimize and standardize the processes of asset identification and reallocation. This is important as the performance influence of sell-offs has been argued to result to a substantial degree from both the deselection of the "right assets" as well as from a more efficient reallocation of the freed-up resources (Burgelman, 1994; Hoskisson \& Johnson, 1992).

Second, learning theory suggests that learning outcomes improve when the object of learning is related to what is already known, and the exchange partners share certain 
commonalities (Lane, Koka, \& Pathak, 2006; Zahra \& George, 2002). In particular, previous research has shown that experience is transferred more effectively when the experience is well understood by the partners involved in the knowledge exchange (Simonin, 1999), when there is substantial similarity among the exchange partners' tasks (Darr \& Kurzberg, 2000), when the exchange partners share a common language (Weber \& Camerer, 2003), or when the transferred experience is characterized by low ambiguity (Simonin, 1999). In the case of sell-offs, the primary knowledge exchange partners are the corporate-level management of the parent company and the divisional managers of the to-be-divested unit. Importantly, for the knowledge exchange between corporate and divisional managers, the above-mentioned preconditions seem to be most closely met when selling related assets.

Third, managers and employees are better able to justify and understand sell-off decisions involving related assets. For closely related businesses, managers and employees possess more intimate knowledge and improved understandings of the rationale for selling a certain business. Consistent with this reasoning, Gopinath and Becker (2000) found that perceptions of procedural justice were higher for transactions with a clear and understandable rationale. Higher levels of perceived procedural justice reduce stress and anxiety and, hence, facilitate learning and knowledge transfer (Lind \& Tyler, 1988).

In sum, we thus hypothesize that knowledge transfer and learning across related sell-offs enhance the performance outcomes of related sell-offs.

Hypothesis 3: Related sell-off experience positively moderates the relationship between related selloffs and firm performance.

\section{Interfirm and Vicarious Learning}

When decomposing a firm's general sell-off experience, it should further be recognized that general experience is not merely a function of internal experience. Instead, as the complexity of sell-offs might overstrain managers' ability to learn from internal experience, prior work has indicated that firms orient to external sources of experience (Haunschild \& Miner, 1997; Mezias \& Lant, 1994). In particular, when lacking sufficient information, firms seek advice from external experts (Kim \& Miner, 2007), or may learn from observing the actions of other firms (Haunschild \& Miner, 1997). In the following, we develop arguments for the moderating influences of external advisors' and industry peers' sell-off experience on the relationship between firm sell-off activity and firm performance.

External advisor sell-off experience. Proponents of organizational learning theory have argued that external knowledge facilitates experience accumulation in organizations and increases a firm's absorptive capacity (Cohen \& Levinthal, 1989). Firms that involve advisors in the selling process may therefore be able to learn more effectively and thus increase subsequent sell-off performance. In general, there are several specific arguments for why external advisor sell-off experience is associated with learning benefits. First, external advisors hold greater sell-off experience and expertise compared to their corporate clients, as the former have specialized in completing these transactions and are able to pool their experience across a wide range of clients (Haspeslagh \& Jemison, 1991). For example, Inkpen highlights how advisors are "required to write summaries of their learning experiences" (2008: 449) and, subsequently, through their rotation across various firms, can reapply this knowledge to 
a specific decision at hand. In addition, learning benefits result from the fact that experienced advisors can usually draw on comprehensive networks. Especially when seeking a buyer and preparing negotiations with potential buyers in an upcoming sell-off, experienced advisors' comprehensive networks provide the advised firm with knowledge advantages across the multiple substages of the sell-off process (i.e., asset identification, asset valuation) relative to firms that are dependent only on their internal experience base. Second, scholars have recognized that learning does not occur "automatically" but requires learning mechanisms such as knowledge codification (Nonaka, 1994; Zander \& Kogut, 1995). External advisors may aid firms in explicating the knowledge that was collected in prior sell-offs and, subsequently, apply this knowledge to the implementation of a focal sell-off. During the asset identification and separation phases, for instance, the explication of knowledge by developing and applying guidelines for identifying operational inefficiencies or by creating manuals for unbundling or detaching assets supports intrafirm knowledge diffusion (Zander \& Kogut, 1995; Zollo \& Winter, 2002).

Psychologically, the involvement of external advisors, who generally carry expert status, is also likely to enhance managers' trust in the internal experience base. Such trust reduces the perceived levels of stress and ambiguity, enabling managers to focus their attention on an upcoming sell-off. Menon and Pfeffer (2003), for instance, showed that organizational members value external knowledge more highly than their internal knowledge. Based on these arguments, we propose the following hypothesis:

Hypothesis 4: The involvement of external advisors positively moderates the relationship between sell-offs and firm performance.

Industry peer sell-off experience. In addition to complementing a firm's internal experience with external experience through the involvement of external advisors, firms are further able to enhance current deal activity by drawing on the experience of industry peers through vicarious learning (Haunschild \& Miner, 1997; Levinthal \& March, 1993; March, 1991; Srinivasan, Haunschild, \& Grewal, 2007). According to evolutionary theory, firms in a given industry possess similar resources and routines (Nelson \& Winter, 1982), thereby exhibiting similar traits that might allow for experience transfer. In the process of vicarious learning, firms collect and analyze competitor information to imitate successful behavior and avoid mistakes (Levitt \& March, 1988; March, 1991; Terlaak \& Gong, 2008).

The benefits of vicarious learning apply across all stages of the sell-off process. Through observing industry peers, for instance, managers can learn about unwanted assets or industries with negative prospects (Nelson \& Winter, 1982), the optimal pricing of sell-offs (Beckman \& Haunschild, 2002), the favorable timing of sell-off decisions (Brauer \& Wiersema, 2012), and successful practices in resource separation and redeployment (Mankins et al., 2008). By studying competitors' actions for clues along these dimensions, firms may be better able to execute a focal sell-off, independent of prior internal experience (Baum, $\mathrm{Li}$, \& Usher, 2000).

Mimicking the actions and procedures of competitors may also have a positive psychological effect on managers involved in ongoing deals. Research on mimetic behavior and industry recipes has shown that managers who engage in imitative behavior have a greater sense of control and a higher perception of decision-making legitimacy (Bowman, 1999; O’Neill, Pouder, \& Buchholtz, 1998). Consequently, increased perceptions of control and 
legitimacy are likely to reduce internal managers' levels of anxiety and stress, leading to improved learning effectiveness.

Hypothesis 5: The extent of sell-off experience by industry peers positively moderates the relationship between sell-offs and firm performance.

\section{Method}

\section{Sample and Data Collection}

To test our hypotheses, we randomly sampled 400 European firms with the only sample selection criterion being their inclusion in one of the countries' major stock market indices. Specifically, the drawn sample includes firms from Austria, Belgium, Denmark, Finland, France, Germany, Great Britain, Italy, the Netherlands, Norway, Spain, Sweden, and Switzerland. We gathered firm data for the period from 1995 to 2009. This time window seemed appropriate as it includes periods of both industry growth and decline, which ensures the basic relevance of sell-offs. General firm and accounting data were retrieved from Compustat and Datastream. Data on sell-offs were collected from the Thomson ONE M\&A database. Due to missing accounting data we had to exclude 107 firms from our sample. Our final sample thus consists of 293 firms. This translates into 2,295 firm-year observations given our longitudinal design. Among those 293 firms, 136 firms did not conduct any selloffs during our period of investigation. These firms, however, were included in our empirical analysis to avoid major endogeneity problems.

\section{Dependent Variable}

Firm performance. Similar to prior research on sell-offs (e.g., Hoskisson \& Johnson, 1992), we assess firm performance using the average ratio of a firm's operating income scaled by firm size in the three years following the focal year of sell-off activity. By employing a three-year postdivestiture window, we ensure that performance measurement is not excessively biased by extraordinary, short-term distortions such as restructuring costs.

\section{Predictor and Moderating Variables}

Sell-off activity. Following prior research (e.g., Hitt et al., 1996), we measured firms' selloff activity as the total number of firm sell-offs in a specific year.

General sell-off experience. We measured general sell-off experience as the number of sell-offs by a firm in the five years prior to the focal year in which additional sell-off activity occurred (Hayward, 2002). A five-year window was used because prior research has shown that firms primarily learn from strategic decisions taken in the preceding three to five years (Hayward, 2002). For robustness purposes, we also used a firm's sell-off volume (in billions of U.S. dollars) in the preceding five years as a proxy for a firm's general sell-off experience. As reported in our section on supplementary analyses below, results remained consistent. But despite receiving consistent results, we believe that from a theoretical perspective the number of sell-offs is a more appropriate proxy for a firm's level of experience compared with the 
overall deal volume. Learning curve theory proposes that learning is generated by knowledge acquired from the repeated actions of organizational members (Arthur \& Huntley, 2005; Berman et al., 2002; Zollo \& Winter, 2002). Instead, a volume- or size-based measure of experience would suggest that organizational members can learn just as effectively from one major transaction as they could from a number of multiple, smaller transactions.

Experience heterogeneity. To assess experience heterogeneity, we first determined the number of different industries (based on four-digit SIC codes), in which the firm conducted its sell-offs in the five years prior to the focal year. On this basis, we calculated a Herfindahl index to measure the dispersion of sell-offs across industries by aggregating the squared shares of total firm sell-offs in the past five years for each industry. To ease interpretation of our measure, we deducted the Herfindahl index from 1.

Experience relatedness. We assessed experience relatedness as the number of sell-offs in the five years preceding the focal year that were related to a firm's core business. We classified a sell-off as related to the core business if the four-digit SIC code of the sold asset was equivalent to the primary SIC code of the firm (e.g., Bergh, Johnson, \& Dewitt, 2008; Bergh \& Lim, 2008; Kaul, 2012).

External advisor experience. We operationalized external advisor involvement as the count of sell-offs in which the seller consulted an external financial advisor in the five-year period preceding the focal year in which renewed sell-off activity occurred.

External industry peer experience. To measure external sell-off experience by industry peers as an indicator for a firm's opportunity to benefit from vicarious learning, we followed prior research (Srinivasan et al., 2007) and calculated the number of sell-offs that took place in the primary industry of the divesting firm (based on four-digit SIC codes) in the preceding five years. We also included this variable as an additional control to control for time-varying industry effects.

\section{Controls}

We further included a number of control variables that are likely to influence a firm's accounting performance. Specifically, we controlled for prior firm performance, firm leverage, firm size, firm diversification, and year effects. All control variables were lagged by one period. Prior firm performance was operationalized as firm operating income scaled by firm size. We included firm performance as a control because prior research suggests that past (pre-restructuring) performance is a strong predictor of future (post-restructuring) performance (e.g., Bergh, 1998; Bergh \& Lim, 2008). Firm leverage was measured as the ratio of total debt to current assets. We thereby capture the ability of a firm to meet its credit obligations with its liquid assets. Firm size was measured as the natural logarithm of total assets (e.g., Laamanen \& Keil, 2008). Both variables are common control variables in studies analyzing the performance implications of corporate sell-off activity (e.g., Berger \& Ofek, 1999; Bergh et al., 2008; Bergh \& Lim, 2008; Brauer \& Schimmer, 2010). Although not all studies have shown a significant influence of these two variables (Bergh \& Lim, 2008), we decided to include these two variables in order to ensure comparability with prior research (Baird, 
Sudharshan, \& Thomas, 1988). We also controlled for the degree of product diversification in our models, as numerous studies have suggested that extensive product diversification is detrimental to corporate performance (e.g., Berger \& Ofek, 1995; Markides, 1995). The degree of product diversification was measured by Jacquemin and Berry's (1979) entropy measure of diversification:

$$
\text { Entropy }=\sum_{i=1}^{N} P_{i} \ln \left(1 / P_{i}\right)
$$

$N$ denotes the total number of segments and $P_{i}$ the sales percentage of the $i$ th segment. The measure was calculated on the basis of the sales in each of the 10 four-digit SIC business segments reported in Compustat. Moreover, our models include year dummies as previous restructuring research has shown that the outcomes of portfolio restructuring activity are sensitive to the timing of deal activity (Hayward, 2003).

\section{Data Analysis}

In contrast to previous studies on sell-offs, we opted for a longitudinal approach. Specifically, we estimated fixed and random effects time series regressions. Given that the Hausman test clearly rejected the applicability of the random effect estimator $(p<.001)$, we report only the results from the fixed effect estimations. To ease interpretation of coefficients, we mean centered all variables that are components of the interaction terms in our regression models (Echambadi \& Hess, 2007).

\section{Results}

Table 1 presents the means, standard deviations, and correlations of all variables used in the study. Table 2 presents the multiple regression results of the explanatory and control variables on three-year post-sell-off firm accounting performance. As indicated by the reported $F$-values, all models are significant.

Given the utilization of a fixed effect estimator in our data analysis, we estimate the increases in model fit caused by the different linear and interaction terms using two different $\log$ likelihood ratio tests. The second last row of Table 2 reporting results of log likelihood ratio tests is based on a comparison of Models 4 to 13 with Model 2, which captures the main effect of focal sell-off activity and the effects of the control variables on firm performance. All $\chi^{2}$ statistics of the log likelihood ratio tests are highly significant and indicate that the inclusion of the predictor variables leads to significant increases in model fit relative to Model 2. Furthermore, we conducted additional log likelihood ratio tests to assess whether the inclusion of the interaction terms leads to significant increases in model fit relative to the models including the respective linear terms. As reported in the bottom row of Table 2, the results from log likelihood ratio tests indicate significant improvements in model fit through the inclusion of the interaction terms relative to the models only including the single terms.

Concerning the hypothesized effects, we find the following results: Our baseline hypothesis proposed that sell-off activity would be positively associated with subsequent firm accounting performance. As shown in Model 2 in Table 2, the level of sell-off activity in a given year is significant and positively related to a firm's accounting performance $(b=0.09$, 


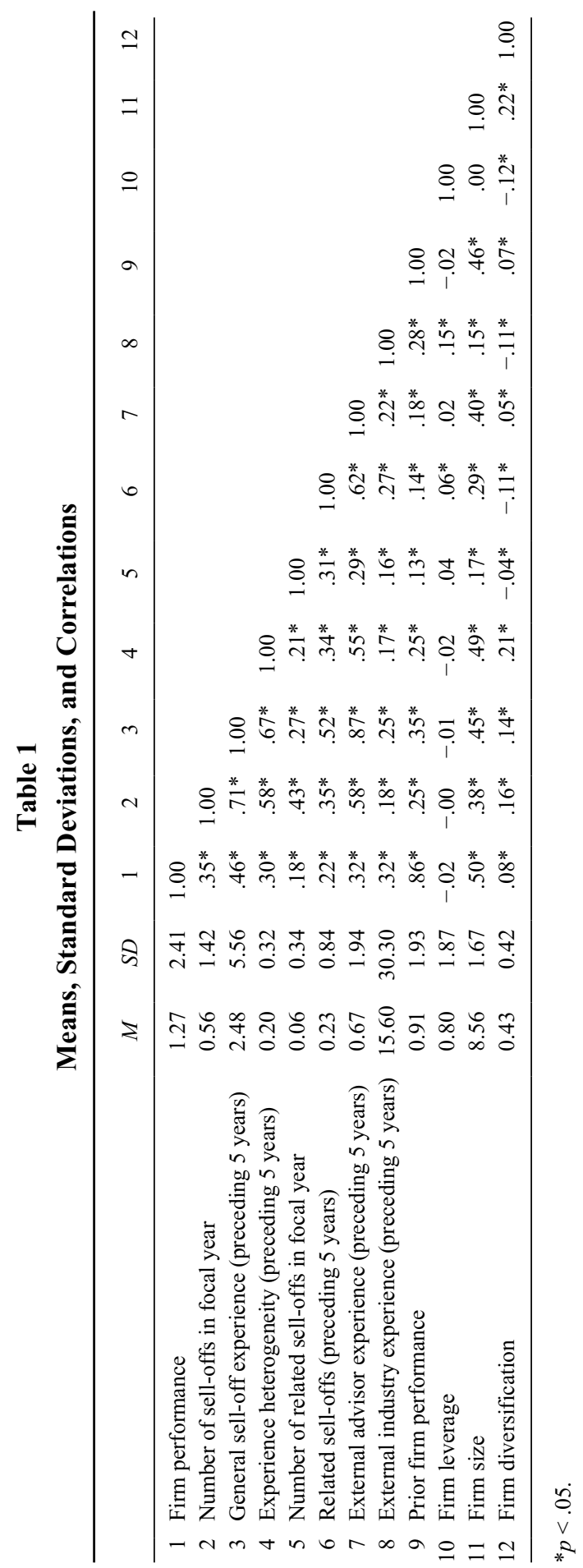




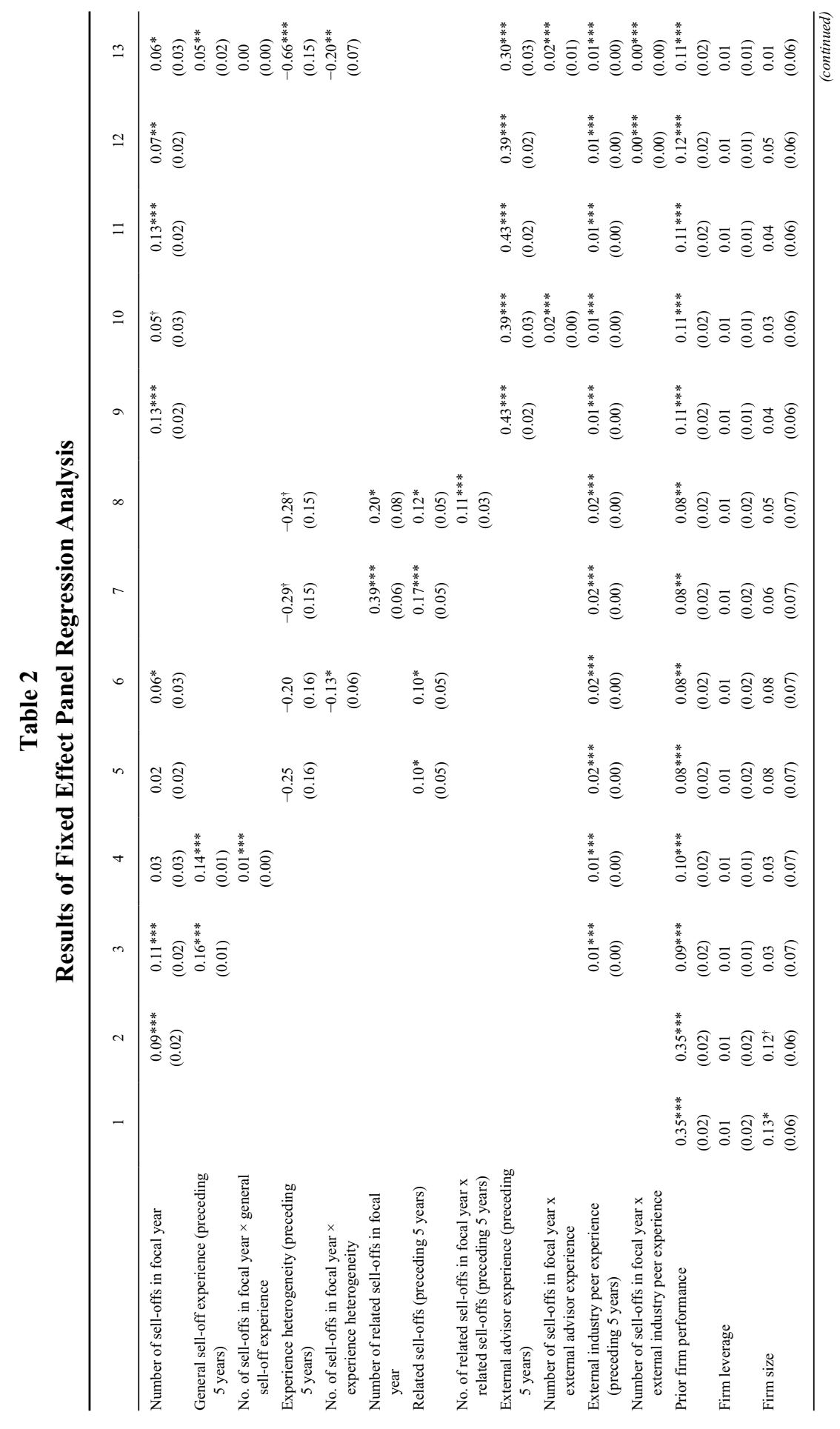




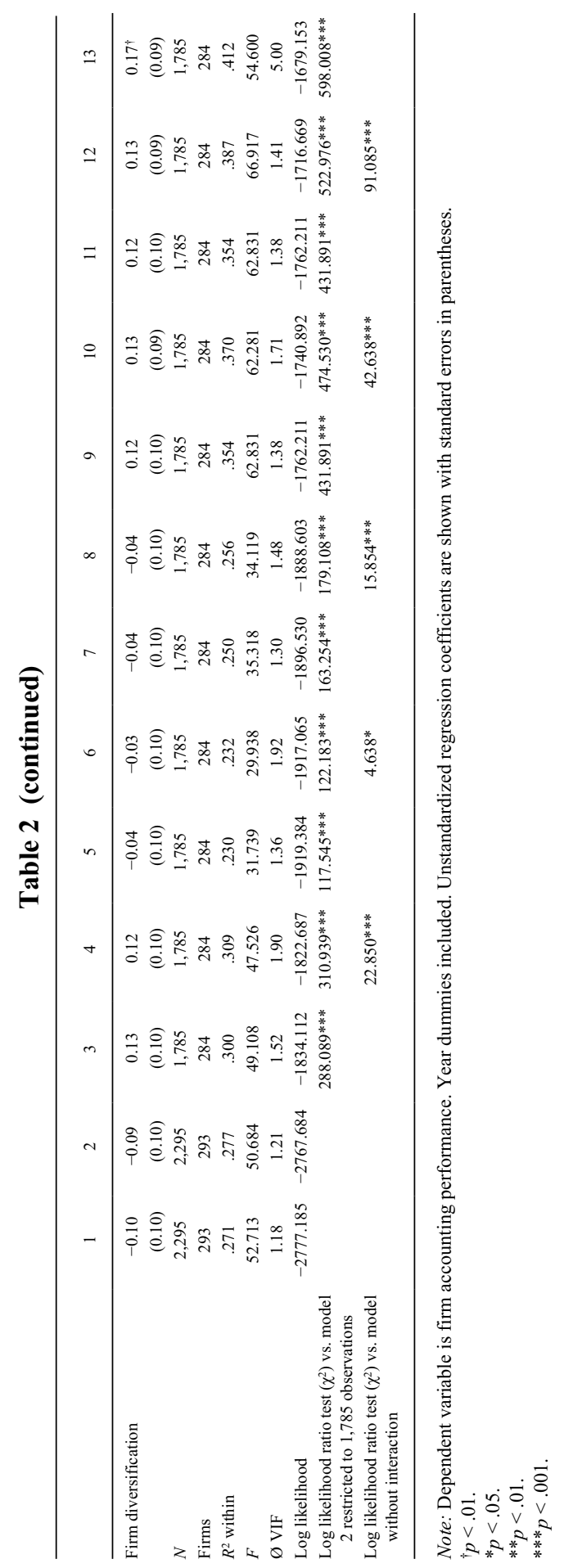




\section{Figure 1 \\ Moderating Effect of General Sell-Off Experience on the Relationship Between Sell- Offs and Firm Accounting Performance}

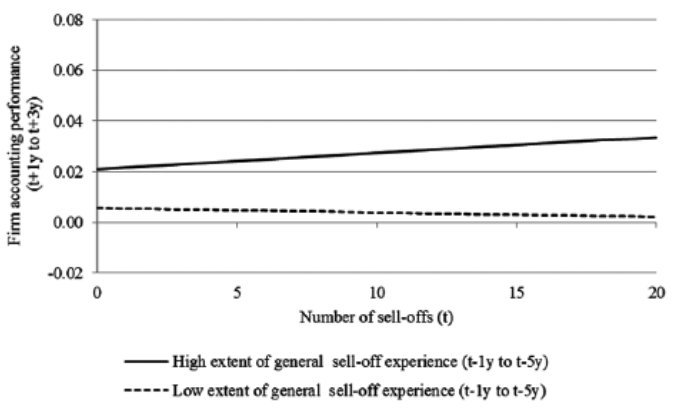

$p<.001)$, as predicted. Model 3 further displays that this positive effect persists $(b=0.11$, $p<.001)$ when including a firm's general sell-off experience in the preceding five years into the model.

Model 4 shows the results for Hypothesis 1. The interaction term between the number of sell-offs in a given year and general sell-off experience accumulated over the preceding fiveyear period is positive and significant $(b=0.01, p<.001)$. The results thus support Hypothesis 1. Figure 1 depicts the effect of general sell-off experience on the relationship between the number of sell-offs in a given year and firm accounting performance. While firms with greater general sell-off experience tend to have, on average, higher initial performance, as indicated by the intercept, the differences in slope are only marginal.

Model 5 shows transitional results to allow for better interpretation of our hypothesized moderating effects. While experience heterogeneity is found to have a negative but not significant direct effect, related sell-off experience is found to have a significant positive direct effect on firm accounting performance subsequent to a firm's focal year sell-off activity. Model 6 then actually shows the results for Hypothesis 2 positing that experience heterogeneity negatively moderates the main relationship of our study. The coefficient of the interaction term between the number of sell-offs in a given year and experience heterogeneity is negative and significant $(b=-0.13, p<.05)$. Hypothesis 2 is thus supported by our empirical results. Figure 2 visualizes the moderating effect.

Model 7 again sets the stage for the subsequent testing of moderating Hypothesis 3 in Model 8. In Model 7, related sell-off activity is found to have a positive significant effect on subsequent firm accounting performance, as expected. Model 8 displays the results for Hypothesis 3, proposing a positive moderating influence of related experience. In line with this prediction, experience gained from related sell-offs in the preceding five years is found to influence the relationship between related sell-offs in the focal year and subsequent accounting performance in a positive and significant way $(b=0.11, p<.001)$. Our empirical results thus lend support for Hypothesis 3. Figure 3 depicts the moderating effect of experience relatedness. 


\section{Figure 2}

\section{Moderating Effect of Experience Heterogeneity on the Relationship Between Sell-Offs} and Firm Accounting Performance

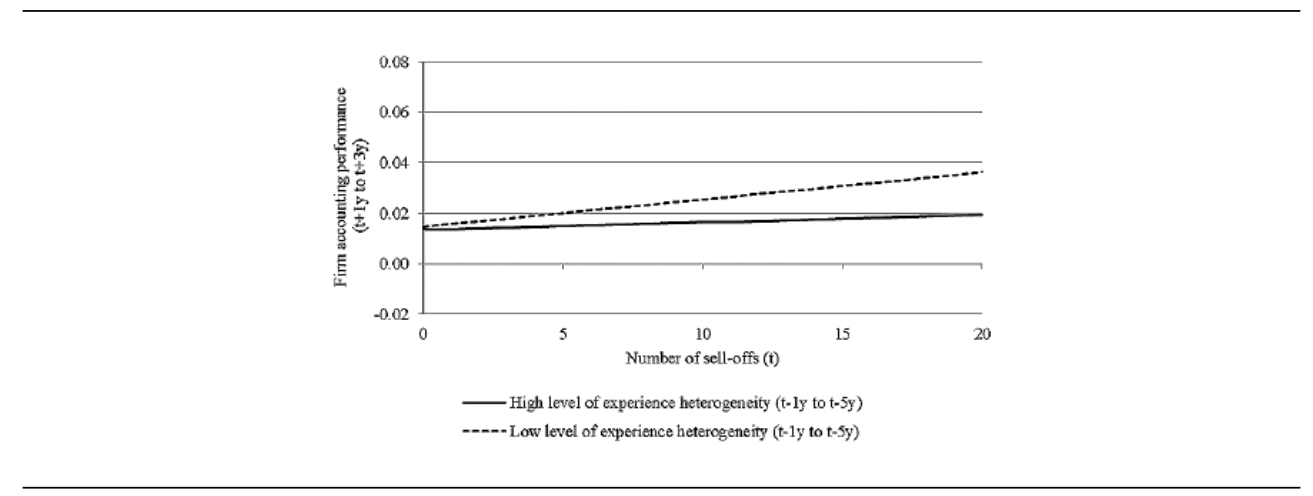

Figure 3

Moderating Effect of Experience Relatedness on the Relationship Between Related Sell-Offs and Firm Accounting Performance

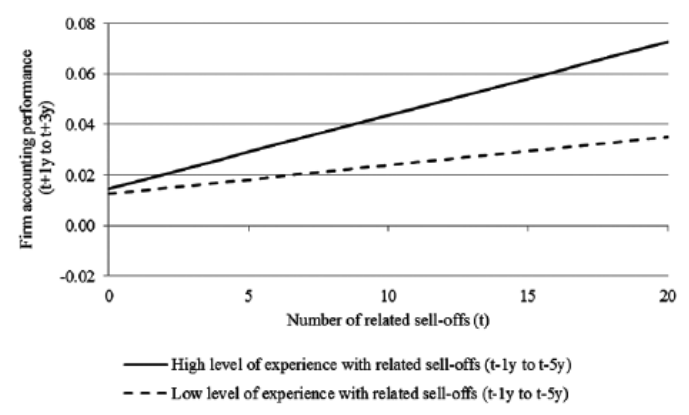

Models 9 and 10 highlight the direct and moderating influence of external advisor experience. Hypothesis 4 suggested that the involvement of external sell-side advisors will positively moderate the relationship between the number of sell-offs in a given year and subsequent firm accounting performance. Model 10 in Table 2 shows that the interaction between the number of sell-offs in a given year and the involvement of external sell-side advisors is positive and significant $(b=0.02, p<.001)$. Thus, Hypothesis 4 is supported by our empirical results. Figure 4 provides a graphical depiction of the effect.

Finally, Hypothesis 5 proposed that sell-off experience by industry peers positively moderates the relationship between a firm's sell-off activity in a focal year and subsequent firm financial performance. While Model 11 shows only the significant and positive direct effect 
Figure 4

Moderating Effect of External Advisor Experience on the Relationship Between SellOffs and Firm Accounting Performance

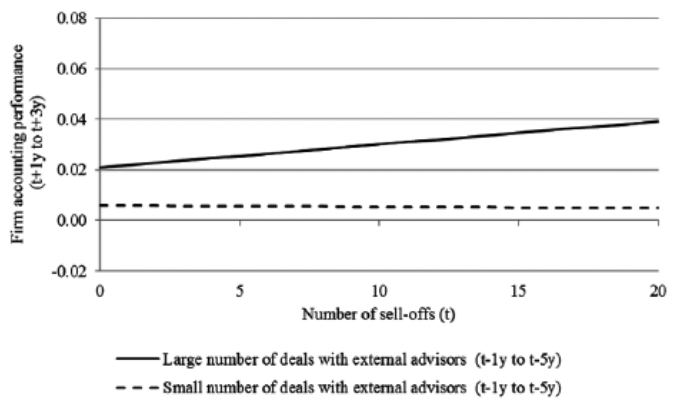

Figure 5

Moderating Effect of External Industry Peer Experience on the Relationship Between Sell-Offs and Firm Accounting Performance

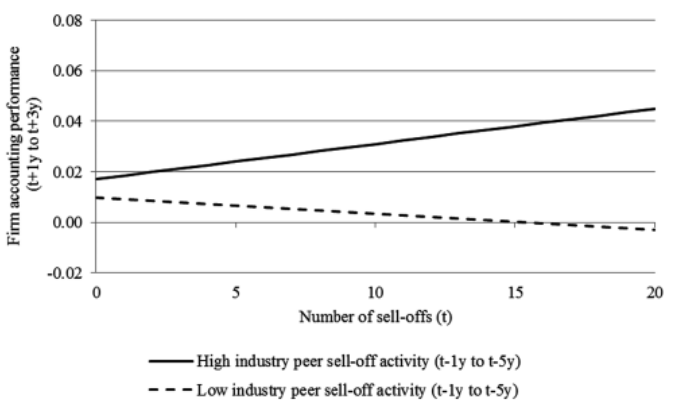

of sell-off experience by industry peers, the interaction term in Model 12 between industry peer sell-off activity in the preceding five-year period and the number of sell-offs in the focal year is positive and significant $(b=0.00, p<.001)$, supporting Hypothesis 5. Figure 5 illustrates the interaction effect graphically.

Model 13 is the full model including the effects of general sell-off experience, experience heterogeneity, external advisor experience, and external industry peer experience. The changes in the significance level of the moderator between general experience and the number of sell-offs indicate that stronger learning benefits are associated with external forms of experience. Some caution, however, is needed when interpreting the results of the full model since supplementary analyses showed slightly higher than generally accepted variance inflation factors for general experience and the interaction term between sell-off activity and general sell-off experience. 


\section{Supplementary Analyses}

To examine the robustness of our results we conducted several robustness checks. First, as mentioned in our operationalization of general sell-off experience, we used the cumulative sell-off volume (in billions of U.S. dollars) in the preceding five years instead of the number of sell-offs in the preceding five years as a proxy for a firm's general sell-off experience. Given that transaction values are not very frequently reported, this reduced the number of firms to 198 (from 293 originally) and the total number of firm-year observations to 1,221 (from 2,295 originally). Since there was no firm in our sample that consistently reported transaction values for all its sell-offs nor a firm that comprehensively reported all transaction values in a given year, we needed to include all firms in our analysis that at least had reported one deal value for the focal year (if any sell-off activity took place in the focal year) and at least one deal value for the preceding five years (if any sell-off activity took place during this period). Results from this analysis support the main findings reported in this study. Second, we also reran our analysis using the total number of prior sell-offs rather than the number of sell-offs in the preceding five years, and received consistent results. Third, we analyzed the role of CEO sell-off experience as opposed to the firm's general sell-off experience. We find that CEO sell-off experience does not significantly moderate the main relationship between a firm's sell-off activity and subsequent firm performance. The effect is nonsignificant regardless of whether a CEO's experience is only considered for the preceding five years or when considering all sell-offs completed during a CEO's tenure. These results suggest that firm-level sell-off experience should not be equated with CEO sell-off experience. This seems reasonable also from a learning perspective. Given the time constraints and only indirect involvement in the key tasks during the different substages of the sell-off process, CEOs are unlikely to be able to accumulate intimate knowledge to the same extent as the dedicated transaction teams working in firms' corporate finance and corporate development units. Fourth, to assess the extent to which our results may be affected by multicollinearity, we ran collinearity diagnostics. Specifically, we calculated variance inflation factors (VIFs) for each independent variable in each of our models. As shown in Table 2, none of the VIFs for Models 1 to 12 had a score greater than 5. Only in the full model (Model 13) the VIF for general sell-off experience (VIF $=13.11)$ and for the moderator between sell-off activity and general sell-off experience (VIF $=13.41$ ) exceeded the generally accepted threshold of 10 , while the average VIF for this model was 5. Furthermore, it is important to note that the potential issue of multicollinearity in the full model has no implications for the study's main results.

\section{Discussion}

Divestitures have become an increasingly important management practice (Dranikoff, Koller, \& Schneider, 2002; Mankins et al., 2008) and a prevalent theme in strategic management research (Brauer, 2006; Lee \& Madhavan, 2010). While the performance implications of acquisitions have generally been found to be negative, empirical research indicates that, on average, divestitures improve a firm's accounting performance (e.g., Bergh, 1998; Hoskisson \& Johnson, 1992; Lee \& Madhavan, 2010; Markides, 1995). But despite the importance of divestitures to firm performance, we have only a very basic understanding of whether and how firms can learn from previous divestitures and, if so, to which extent learning may help improve subsequent divestiture outcome (Brauer, 2006). 
Drawing on learning theory, we analyze whether different forms of internal and external experience that are associated with different learning processes have disparate (moderating) influences on the relationship between a firm's sell-off activity and firm performance. First, we find that general divestiture experience strengthens the positive influence of sell-off activity on subsequent firm performance. Consistent with prior research (e.g., Arthur \& Huntley, 2005), the finding suggests that there is also a "learning curve" for cost reduction measures such as divestitures. However, this effect is found to be marginal. The marginal effect essentially provides empirical evidence for the necessity to decompose general experience, and to consider the extent of heterogeneity and relatedness of internal experience. Specifically, we observe that greater extents of experience heterogeneity negatively moderate the relationship between a firm's sell-off activity and subsequent financial performance. This negative moderation effect is argued to result from the absence of deep knowledge and a greater likelihood for erroneous experience transfers to current deal activity. In contrast, empirical results suggest that related experience positively influences the relationship between related deals and firm performance. In line with the notion of absorptive capacity, this can be explained by the greater proximity of related assets to the core business, which facilitates more effective learning and knowledge transfer. Moreover, "organizational forgetting" may set in more slowly when a firm divests assets closely related to its core business because the sale of a related asset has a greater effect on organizational identity, and managers have a better understanding of the rationale for the transaction and its implications (de Holan \& Phillips, 2004). In total, this results in greater "returns to (related) experience."

Furthermore, our findings underscore the notion that the idiosyncrasy and complexity of sell-offs make external experience an additional source for enhancing ongoing deal activity. Specifically, we find that external experience through the involvement of advisors positively influences the relationship between sell-offs and firm accounting performance. Finally, our results suggest that external experience from observing competitors' sell-off behavior positively moderates the relationship between a firm's sell-off activity and subsequent firm accounting performance. This result indicates the importance of considering industry divestiture activity when evaluating the economic outcomes of divestitures. Recently, Brauer and Wiersema (2012) provided initial empirical evidence that investors' responses to firm divestitures are influenced by the prevalence of divestiture activity in an industry. Utilizing imitation theory, they argued and found that firms that divest early or late in an industry divestiture wave generate significantly higher returns than firms that divest at the peak of a wave. Their finding that firms divesting in the dissipation phase of a wave generate the highest returns is somewhat complementary to our finding that firms may benefit from being able to draw on a substantial pool of industry peer divestiture activity.

\section{Implications for Research on Divestitures}

This study extends research on divestitures in several ways. First, this article examines the moderating effects of internal and external experience on the relationship between sell-offs and firm accounting performance. In contrast, prior studies have predicted a linear, direct effect of general experience on divestiture outcome (e.g., Bergh \& Lim, 2008; Lee \& Madhavan, 2010). The moderation approach allows for a distinction between the direct influence of the actual event (i.e., sell-off activity) on firm performance ("restructuring effect") and the additional influence of the distinct types of experience on firm performance ("experience effect"). 
Second, this article extends the theoretical repertoire to explain sell-offs' positive performance outcomes beyond the established perspectives of transaction cost economics and agency theory (Afshar et al., 1992; John \& Ofek, 1995; Markides \& Singh, 1997). By adopting a learning perspective, we complement recent work that has used absorptive capacity and organizational improvisation arguments to explain the outcomes of sell-offs (i.e., Bergh \& Lim, 2008). Going beyond this work, however, we propose that learning effects are multifaceted in the context of sell-offs, and may even have a negative moderating influence. In addition, our study extends the existing focus on internal forms of experience in divestiture research by highlighting the role of external experience. Results suggest that firms are able to enhance the performance of ongoing divestiture activity by closely observing competitors' past sell-off activity and/or by drawing on external advisors' sell-off experience.

A third contribution of this article to divestiture research relates to the distinction between divestitures and acquisitions. While earlier work has often treated divestitures as mirror images of acquisitions (e.g., Buchholtz, Lubatkin, \& O’Neill, 1999), a comparison of our findings with earlier work on acquisitions brings further relevant differences to light. In particular, acquisition research predicted and found a positive influence of experience heterogeneity on acquisition outcome (e.g., Hayward, 2002). The different role of experience heterogeneity in acquisitions and sell-offs may result from the disruptive effects of sell-offs on an organization's social network. This social network is generally understood as one of the primary mechanisms through which organizational learning occurs and knowledge is created, retained, and transferred (Argote \& Miron-Spektor, 2011). Divisional managers who are an integral part of an organization's social network and who gather firsthand experience on how to conduct sell-offs, however, are typically transferred to the buyer after the completion of a sell-off, or leave the company altogether (Brauer, 2009). This is an important difference between acquisitions and divestitures, and makes the development of deep knowledge and cross-divisional knowledge sharing much more difficult in the latter case. Furthermore, our finding on the positive moderating influence of advisor involvement adds to the controversial discussion on the usefulness of advisor engagement in portfolio restructuring literature (e.g., Beckman \& Haunschild, 2002; Hayward, 2002). Prior acquisition research has largely found evidence for a direct, negative influence of advisor involvement on firm acquisition outcomes (Hayward, 2002, 2003; Kesner, Shapiro, \& Sharma, 1994). A potential explanation for the positive direct and positive moderating influence of advisors in sell-offs could be that sell-offs are typically initiated by the divesting firm. This limits the negative influence of advisors" "bias for transaction" that is characteristic of acquisitions (Kolasinski \& Kothari, 2008).

\section{Implications for Organizational Learning Theory}

Beyond divestiture research, this article contributes to organizational learning theory. Early research on organizational learning in strategic contexts adopted a traditional learning curve perspective that assumes that learning originates from a simple replication of previous experience (see Barkema \& Schijven, 2008 for a review). We show that this view is only partially accurate when applied to sell-offs. The degree to which general experience has positive or negative moderating influence is shown to largely depend on the composition of general experience. Specifically, our findings on experience heterogeneity show that the causal ambiguity that goes along with sell-offs completed in many different industries may 
actually lead to negative learning effects (Hypothesis 2). In contrast, firms are found to learn particularly effectively from and across related transactions (Hypothesis 3 ). By decomposing general experience, we are thus able to more accurately determine the boundary conditions under which experience is either a "good or a bad teacher" (March, 2010: 101).

Second, our findings contribute to extant debates on the origins and effects of superstitious learning. Most prior work focused on the occurrence of superstitious learning in expansionary strategic decisions such as acquisitions, alliances, or product expansions (e.g., Heimeriks, 2010; Zollo, 2009). In these decision settings, researchers have argued that a premature sense of success prevents managers from scrutinizing the exact relationship among actions and outcomes (Kim, Kim, \& Miner, 2009). This study is among the first to investigate the occurrence of superstitious learning in contractionary settings where overconfidence seems unlikely to be the major reason for misjudging cause-effect relationships. Instead, we propose that heterogeneous experience does not necessarily create a false sense of competence but rather leads to oversimplification in form of false or inaccurate rules of thumb. In contractionary settings, false or inaccurate rules of thumb are likely to emerge because cross-divisional knowledge sharing is complicated by the involvement of a large number of divisional managers, and the fact that divisional managers of past sold off units have typically left the seller company. As a result, remaining managers are left with half histories. Not having the full picture due to industry differences and in the absence of detailed personal accounts of the practices that were used makes it even more difficult to detect erroneous experience transfer in sell-offs.

The current study's findings further contribute to organizational learning theory by not only considering internal experience but also by investigating the moderating role of external experience. The consideration of both internal and external experience seems theoretically meaningful as the idiosyncrasy and complexity of sell-offs may require both forms of experience. Specifically, organizational learning theory predicts that vicarious learning is particularly useful under conditions of ambiguity and threat (Haunschild \& Miner, 1997; Miner \& Mezias, 1996), which characterize divestiture contexts. We extend this theoretical reasoning by proposing that learning by observing may enhance divestiture outcome because corporate managers are not subject to the repeated, emotional constraints that accompany a series of divestitures over time. Instead, the more "relaxed" emotional disposition of managers observing competitors' sell-off activity may enable them to better identify the key cause-effect relationships in sell-offs without having to complete the deal themselves. Beyond "learning by observing," we indicate that external advisors provide firms with the opportunity for interfirm learning. While prior work highlighted the role of board interlocks (Beckman \& Haunschild, 2002), alliance and joint venture networks (Inkpen \& Dinur, 1998; Zollo, Reuer, \& Singh, 2002), or expert networks (Reagans \& McEvily, 2003), we highlight the role of external advisors when transferring knowledge across firms. Other than board interlocks or firm networks, external advisors enable the acquisition of in-depth external knowledge without the threat of knowledge outflows or intellectual property infringements (e.g., Perri \& Andersson, 2014). Furthermore, the inclusion of external advisors may not only facilitate interfirm learning but also promote firm internal learning as advisors support knowledge codification and transmission of the firm.

\section{Practical Implications}

The study's findings also provide insights and tentative prescriptions for managers. In particular, we indicate how internal and external experience may be leveraged in divestitures. 
In line with prior research on divestitures, this study indicates that divestitures are a viable means of improving firm (accounting) performance (e.g., Bergh, 1998; Hoskisson \& Johnson, 1992; Markides, 1995). In addition to prior studies on divestiture performance, however, this study suggests that performance variations may originate from differences in the composition of a firm's general divestiture experience. While the accumulation of past experience is generally found to positively affect the relationship between divestiture activity and firm performance, the effect seems rather marginal. Instead, our findings emphasize that the composition of general experience should be examined more carefully. Our empirical findings on the effects of experience heterogeneity clearly indicate that managers should be cautious when drawing on the "lessons learned" from past transactions. A careful comparison of structural deal characteristics and industry conditions seems warranted to prevent managers from drawing incorrect inferences from too dissimilar past transactions. Results thus suggest that managers should implement mechanisms (e.g., management information systems; transaction manuals) that ensure that the knowledge gained from prior transactions is adequately codified and stored. Such knowledge can then be consulted in subsequent transactions. Furthermore, the results on experience effects from sell-offs involving related assets indicate that the 'stickiness' of experience and the associated learning benefits may be particularly pronounced when divesting related assets. Moreover, our findings advise managers to keep a close eye on competitors' divestiture activity and/or to hire a "second pair of eyes" in the form of advisor involvement. Both forms of external experience seem helpful in complementing and further leveraging the internal experience base. Finally, learning theory suggests that managers not only are advised to establish appropriate formal learning and knowledge management systems but also should create an organizational climate that helps reduce employees' strong feelings of ambiguity and anxiety regarding sell-offs. Effectively learning to divest seems to require mindfulness with respect to "organizational hard- and software."

\section{Limitations and Future Research}

The findings of this study should be seen in the light of the following limitations. First, our sample consists of publicly listed firms from 13 different European countries. Though covering multiple countries, the overall cultural context is not likely to vary distinctively across our sample of firms. But since managers' perception of sell-offs, for instance, may be argued to differ across distinct cultural contexts, future research may want to study culturally more distinct settings (e.g., the United States or Asia) to test whether our findings hold under these conditions. Second, with no strong theoretical basis on how to operationalize the different forms of experience, we followed prior empirical research on acquisitions and divestitures (Bergh et al., 2008; Bergh \& Lim, 2008; Kaul, 2012), using four-digit SIC code operationalizations for our experience variables. For robustness purposes, we also reran our analyses using two-digit SIC code operationalizations. With the exception of our findings on the moderation effect involving experience relatedness, results remained robust.

A third limitation results from our exclusive reliance on secondary data. While the benefits of a psychoanalytical approach have been stressed in organization science research (Covington \& Omelich, 1987), few studies in strategic management research have incorporated emotions in their theoretical reasoning to explain the effectiveness of learning in strategic decision making. While this study incorporates theoretical arguments on how the emotional disposition may affect learning in sell-offs, the absence of primary data prevents 
us to make more substantial claims on the true extent to which emotional dispositions influence experience and knowledge transfer. Future research on organizational learning would thus strongly benefit from studies attempting to measure the emotional dispositions that are associated with different strategic decisions. Such research efforts are likely to considerably expand our understanding of the conditions influencing the effectiveness of organizational learning.

Through the reliance on secondary data, we were further unable to accurately assess how the different types of experience may affect the substages of the sell-off process in distinct ways. Using survey based designs, research on strategic decision-making processes (e.g., Fredrickson, 1984; Papadakis, Lioukas, \& Chambers, 1998) has captured the disparate influence of key decision process characteristics (i.e., comprehensiveness, politics) along the different substages of the decision-making process - namely situation diagnosis, alternative generation, alternative evaluation, decision integration. Similar survey-based studies are thus called for in the organizational learning and restructuring research domain to assess the potentially disparate influence of the different forms of experience in the different substages of transaction processes.

Fourth, this study did not control for the specific motives of a sell-off. Future research could extend these findings by also considering the specific motives for divesting as an important contingency factor influencing learning effectiveness. Strategic transactions as part of a "corporate divestiture program," for instance, are likely to be initiated with greater foresight than opportunistic transactions (Brauer \& Schimmer, 2010). Strategically motivated transactions thus seem to bear comparatively greater potential for learning transfer.

A final limitation of our study relates to its inability to fully tease out the extent to which the multiple forms of learning co-occur. Superstitious learning, for instance, may obviously not just occur as part of a firm's individual experiential learning efforts but also occur as part of interfirm or vicarious learning endeavors. Greater extents of information asymmetries due to the fact that competitor and advisor experience are not always fully accessible complicate the rightful assessment of cause-effect relationships and, thus, heighten the risk of superstitious learning. Based on our results, however, we can say that superstitious learning is at least not likely to overpower the positive effects associated with interfirm and vicarious learning.

\section{References}

Adler, P. S., \& Clark, K. B. 1991. Behind the learning-curve-A sketch of the learning-process. Management Science, 37: 267-281.

Afshar, K. A., Taffler, R. J., \& Sudarsanam, P. S. 1992. The effect of corporate divestments on shareholder wealthThe UK experience. Journal of Banking \& Finance, 16: 115-135.

Anand, B. N., \& Khanna, T. 2000. Do firms learn to create value? The case of alliances. Strategic Management Journal, 21: 295-315.

Argote, L., \& Miron-Spektor, E. 2011. Organizational learning: From experience to knowledge. Organization Science, 22: 1123-1137.

Arthur, J. B., \& Huntley, C. L. 2005. Ramping up the organizational learning curve: Assessing the impact of deliberate learning on organizational performance under gainsharing. Academy of Management Journal, 48: 1159-1170.

Baird, I. S., Sudharshan, D., \& Thomas, H. 1988. Addressing temporal change in strategic groups analysis-A 3-mode factor analysis approach. Journal of Management, 14: 425-439.

Barkema, H. G., \& Schijven, M. 2008. How do firms learn to make acquisitions? A review of past research and an agenda for the future. Journal of Management, 34: 594-634. 
Barkema, H. G., Shenkar, O., Vermeulen, F., \& Bell, J. H. J. 1997. Working abroad, working with others: How firms learn to operate international joint ventures. Academy of Management Journal, 40: 426-442.

Barth, M. E., \& Clinch, G. 1998. Revalued financial, tangible, and intangible assets: Associations with share prices and non-market-based value estimates. Journal of Accounting Research, 36: 199-233.

Baum, J. A. C., Li, S. X., \& Usher, J. M. 2000. Making the next move: How experiential and vicarious learning shape the locations of chains' acquisitions. Administrative Science Quarterly, 45: 766-801.

Becker, T. E., Billings, R. S., Eveleth, D. M., \& Gilbert, N. L. 1996. Foci and bases of employee commitment: Implications for job performance. Academy of Management Journal, 39: 464-482.

Beckman, C. M., \& Haunschild, P. R. 2002. Network learning: The effects of partners' heterogeneity of experience on corporate acquisitions. Administrative Science Quarterly, 47: 92-124.

Berger, P. G., \& Ofek, E. 1995. Diversification's effect on firm value. Journal of Financial Economics, 37: 39-65.

Berger, P. G., \& Ofek, E. 1999. Causes and effects of corporate refocusing programs. Review of Financial Studies, 12: 311-345.

Bergh, D. D. 1995. Size and relatedness of units sold-An agency theory and resource-based perspective. Strategic Management Journal, 16: 221-239.

Bergh, D. D. 1997. Predicting divestiture of unrelated acquisitions: An integrative model of ex ante conditions. Strategic Management Journal, 18: 715-731.

Bergh, D. D. 1998. Product-market uncertainty, portfolio restructuring, and performance: An informationprocessing and resource-based view. Journal of Management, 24: 135-155.

Bergh, D. D., Johnson, R. A., \& Dewitt, R.-L. 2008. Restructuring through spin-off or sell-off: Transforming information asymmetries into financial gain. Strategic Management Journal, 29: 133-148.

Bergh, D. D., \& Lim, E. N. K. 2008. Learning how to restructure: Absorptive capacity and improvisational views of restructuring actions and performance. Strategic Management Journal, 29: 593-616.

Berman, S. L., Down, J., \& Hill, C. W. L. 2002. Tacit knowledge as a source of competitive advantage in the National Basketball Association. Academy of Management Journal, 45: 13-31.

Bowman, C. 1999. Action-led strategy and managerial self-confidence. Journal of Managerial Psychology, 14: 558-568.

Brauer, M. 2006. What have we acquired and what should we acquire in divestiture research? A review and research agenda. Journal of Management, 32: 751-785.

Brauer, M. 2009. Corporate and divisional manager involvement in divestitures - A contingent analysis. British Journal of Management, 20: 341-362.

Brauer, M., \& Schimmer, M. 2010. Performance effects of corporate divestiture programs. Journal of Strategy and Management, 3: 84-109.

Brauer, M., \& Wiersema, M. F. 2012. Industry divestiture waves: How a firm's position influences investor returns. Academy of Management Journal, 55: 1472-1492.

Buchholtz, A. K., Lubatkin, M., \& O’Neill, H. M. 1999. Seller responsiveness to the need to divest. Journal of Management, 25: 633-652.

Burgelman, R. A. 1994. Fading memories-A process theory of strategic business exit in dynamic environments. Administrative Science Quarterly, 39: 24-56.

Campbell, A., Goold, M., \& Alexander, M. 1995. Corporate strategy: The quest for parenting advantage. Harvard Business Review, 73: 120-132.

Cohen, W. M., \& Levinthal, D. A. 1989. Innovation and learning-The 2 faces of R-and-D. Economic Journal, 99 : 569-596.

Covington, M. V., \& Omelich, C. L. 1987. I knew it cold before the exam-A test of the anxiety-blockage hypothesis. Journal of Educational Psychology, 79: 393-400.

Darr, E., \& Kurzberg, T. 2000. An investigation of partner similarity dimensions on knowledge transfer. Organizational Behavior and Human Decision Processes, 82: 28-44.

Datta, S., Iskandar-Datta, M., \& Raman, K. 2003. Value creation in corporate asset sales: The role of managerial, performance and lender monitoring. Journal of Banking \& Finance, 27: 351-375.

de Holan, P. M., \& Phillips, N. 2004. Remembrance of things past? The dynamics of organizational forgetting. Management Science, 50: 1603-1613.

Dranikoff, L., Koller, T., \& Schneider, A. 2002. Divestiture: Strategy's missing link. Harvard Business Review, 80: $75-83$.

Duhaime, I. M., \& Grant, J. H. 1984. Factors influencing divestment decision-making-Evidence from a field study. Strategic Management Journal, 5: 301-318. 
Dutton, J. M., \& Thomas, A. 1984. Treating progress functions as a managerial opportunity. Academy of Management Review, 9: 235-247.

Echambadi, R., \& Hess, J. D. 2007. Mean-centering does not alleviate collinearity problems in moderated multiple regression models. Marketing Science, 26: 438-445.

Fredrickson, J. W. 1984. The comprehensiveness of strategic decision-processes-Extension, observations, futuredirections. Academy of Management Journal, 27: 445-466.

French, J. R. P., \& Caplan, R. D. 1973. Organizational stress and individual strain. In J. Marrow (Ed.), The failure of success: 30-66. New York: American Management Association.

Gopinath, C., \& Becker, T. E. 2000. Communication, procedural justice, and employee attitudes: Relationships under conditions of divestiture. Journal of Management, 26: 63-83.

Haleblian, J., \& Finkelstein, S. 1999. The influence of organizational acquisition experience on acquisition performance: A behavioral learning perspective. Administrative Science Quarterly, 44: 29-56.

Harrigan, K. R. 1981. Deterrents to divestiture. Academy of Management Journal, 24: 306-323.

Harrigan, K. R. 1985. Exit barriers and vertical integration. Academy of Management Journal, 28: 686-697.

Haspeslagh, P. C., \& Jemison, D. B. 1991. Managing acquisitions: Creating value through corporate renewal. New York: Free Press.

Haunschild, P. R., \& Miner, A. S. 1997. Modes of interorganizational imitation: The effects of outcome salience and uncertainty. Administrative Science Quarterly, 42: 472-500.

Hayward, M. L. A. 2002. When do firms learn from their acquisition experience? Evidence from 1990-1995. Strategic Management Journal, 23: 21-39.

Hayward, M. L. A. 2003. Professional influence: The effects of investment banks on clients' acquisition financing and performance. Strategic Management Journal, 24: 783-801.

Heimeriks, K. H. 2010. Confident or competent? How to avoid superstitious learning in alliance portfolios. Long Range Planning, 43: 57-84.

Hitt, M. A., Hoskisson, R. E., Johnson, R. A., \& Moesel, D. D. 1996. The market for corporate control and firm innovation. Academy of Management Journal, 39: 1084-1119.

Holmqvist, M. 2004. Experiential learning processes of exploitation and exploration within and between organizations: An empirical study of product development. Organization Science, 15: 70-81.

Hoskisson, R. E., \& Hitt, M. A. 1994. Downscoping: How to tame the diversified firm. New York: Oxford University Press.

Hoskisson, R. E., \& Johnson, R. A. 1992. Corporate restructuring and strategic change-The effect on diversification strategy and research-and-development intensity. Strategic Management Journal, 13: 625-634.

Hoskisson, R. E., Johnson, R. A., \& Moesel, D. D. 1994. Corporate divestiture intensity in restructuring firmsEffects of governance, strategy, and performance. Academy of Management Journal, 37: 1207-1251.

Inkpen, A. C. 2008. Research notes and commentaries: Knowledge transfer and international joint ventures: The case of Nummi and General Motors. Strategic Management Journal, 29: 447-453.

Inkpen, A. C., \& Dinur, A. 1998. Knowledge management processes and international joint ventures. Organization Science, 9: 454-468.

Jacquemin, A. P., \& Berry, C. H. 1979. Entropy measure of diversification and corporate growth. Journal of Industrial Economics, 27: 359-369.

John, K., \& Ofek, E. 1995. Asset sales and increase in focus. Journal of Financial Economics, 37: 105-126.

Kaul, A. 2012. Technology and corporate scope: Firm and rival innovation as antecedents of corporate transactions. Strategic Management Journal, 33: 347-367.

Kesner, I. F., Shapiro, D. L., \& Sharma, A. 1994. Brokering mergers-An agency theory perspective on the role of representatives. Academy of Management Journal, 37: 703-721.

Kim, J.-Y., Kim, J.-Y., \& Miner, A. S. 2009. Organizational learning from extreme performance experience: The impact of success and recovery experience. Organization Science, 20: 958-978.

Kim, J. Y., \& Miner, A. S. 2007. Vicarious learning from the failures and near-failures of others: Evidence from the US commercial banking industry. Academy of Management Journal, 50: 687-714.

Kolasinski, A. C., \& Kothari, S. P. 2008. Investment banking and analyst objectivity: Evidence from analysts affiliated with mergers and acquisitions advisors. Journal of Financial and Quantitative Analysis, 43: 817-842.

Krishnaswami, S., \& Subramaniam, V. 1999. Information asymmetry, valuation, and the corporate spin-off decision. Journal of Financial Economics, 53: 73-112.

Laamanen, T., \& Keil, T. 2008. Performance of serial acquirers: Toward an acquisition program perspective. Strategic Management Journal, 29: 663-672. 
Lane, P. J., Koka, B. R., \& Pathak, S. 2006. The reification of absorptive capacity: A critical review and rejuvenation of the construct. Academy of Management Review, 31: 833-863.

Lawler, E. E., \& Hall, D. T. 1970. Relationship of job characteristics to job involvement, satisfaction, and intrinsic motivation. Journal of Applied Psychology, 54: 305-312.

Lee, D., \& Madhavan, R. 2010. Divestiture and firm performance: A meta-analysis. Journal of Management, 36 : 1345-1371.

Levinthal, D. A., \& March, J. G. 1993. The myopia of learning. Strategic Management Journal, 14: 95-112.

Levitt, B., \& March, J. G. 1988. Organizational learning. Annual Review of Sociology, 14: 319-340.

Lind, E. A., \& Tyler, T. 1988. The social psychology of procedural justice. New York: Plenum Press.

Lyles, M. A. 1994. The impact of organizational learning on joint venture formations. International Business Review, 3: 459-467.

Mankins, M. C., Harding, D., \& Weddigen, R. M. 2008. How the best divest. Harvard Business Review, 86: $92-99$.

March, J. G. 1991. Exploration and exploitation in organizational learning. Organization Science, 2: 71-87.

March, J. G. 2010. The ambiguities of experience. Ithaca, NY: Cornell University Press.

Markides, C. 1992. Consequences of corporate refocusing-Ex ante evidence. Academy of Management Journal, 35: 398-412.

Markides, C. C. 1995. Diversification, restructuring, and economic performance. Strategic Management Journal, 16: 101-118.

Markides, C., \& Singh, H. 1997. Corporate restructuring: A symptom of poor governance or a solution to past managerial mistakes? European Management Journal, 15: 213-219.

Menon, T., \& Pfeffer, J. 2003. Valuing internal vs. external knowledge: Explaining the preference for outsiders. Management Science, 49: 497-513.

Mezias, S., \& Lant, T. 1994. Mimetic learning and the evolution of organizational populations. In J. Baum \& J. Singh (Eds.), Evolutionary dynamics of organizations: 179-193. New York: Oxford University Press.

Miner, A. S., \& Mezias, S. J. 1996. Ugly duckling no more: Pasts and futures of organizational learning research. Organization Science, 7: 88-99.

Mulherin, J. H., \& Boone, A. L. 2000. Comparing acquisitions and divestitures. Journal of Corporate Finance, 6: 117-139.

Nelson, R. R., \& Winter, S. G. 1982. An evolutionary theory of economic change. Cambridge, MA: Belknap.

Nonaka, I. 1994. A dynamic theory of organizational knowledge creation. Organization Science, 5: 14-37.

O’Neill, H. M., Pouder, R. W., \& Buchholtz, A. K. 1998. Patterns in the diffusion of strategies across organizations: Insights from the innovation diffusion literature. Academy of Management Review, 23: 98-114.

Papadakis, V. M., Lioukas, S., \& Chambers, D. 1998. Strategic decision-making processes: The role of management and context. Strategic Management Journal, 19: 115-147.

Parasuraman, S., \& Alutto, J. A. 1981. An examination of the organizational antecedents of stressors at work. Academy of Management Journal, 24: 48-67.

Perri, A., \& Andersson, U. 2014. Knowledge outflows from foreign subsidiaries and the tension between knowledge creation and knowledge protection: Evidence from the semiconductor industry. International Business Review, 23: 63-75.

Reagans, R., \& McEvily, B. 2003. Network structure and knowledge transfer: The effects of cohesion and range. Administrative Science Quarterly, 48: 240-267.

Rosenbluth, J. E. 2002. Corporate divestitures-A selective guide to the key business and legal issues. Investment Lawyer, 9: 3-7.

Schipper, K., \& Smith, A. 1983. Effects of recontracting on shareholder wealth-The case of voluntary spin-offs. Journal of Financial Economics, 12: 437-467.

Schwenk, C. R. 1984. Cognitive simplification processes in strategic decision-making. Strategic Management Journal, 5: 111-128.

Shimizu, K., \& Hitt, M. A. 2005. What constrains or facilitates divestitures of formerly acquired firms? The effects of organizational inertia. Journal of Management, 31: 50-72.

Simonin, B. L. 1999. Ambiguity and the process of knowledge transfer in strategic alliances. Strategic Management Journal, 20: 595-623.

Srinivasan, R., Haunschild, P., \& Grewal, R. 2007. Vicarious learning in new product introductions in the early years of a converging market. Management Science, 53: 16-28.

Staw, B. M., Sandelands, L. E., \& Dutton, J. E. 1981. Threat-rigidity effects in organizational behavior-A multilevel analysis. Administrative Science Quarterly, 26: 501-524. 
Terlaak, A., \& Gong, Y. 2008. Vicarious learning and inferential accuracy in adoption processes. Academy of Management Review, 33: 846-868.

Van de Ven, A. H., \& Lin, T. 1989. Rational and superstitious learning in the temporal development of innovations. Paper presented at the Conference on Organizational Learning, Pittsburgh, PA.

Walsh, J. P. 1989. Doing a deal: Merger and acquisition negotiations and their impact upon target company top management turnover. Strategic Management Journal, 10: 307-322.

Weber, R. A., \& Camerer, C. F. 2003. Cultural conflict and merger failure: An experimental approach. Management Science, 49: 400-415.

Winnicott, D. 1962. The maturational processes and facilitating environment. London: Horgath Press.

Winnicott, D. 1980. Playing \& reality. Harmondsworth: Penguin.

Yelle, L. E. 1979. The learning curve: Historical review and comprehensive survey. Decision Sciences, 10: $302-328$.

Zahra, S. A., \& George, G. 2002. Absorptive capacity: A review, reconceptualization, and extension. Academy of Management Review, 27: 185-203.

Zander, U., \& Kogut, B. 1995. Knowledge and the speed of the transfer and imitation of organizational capabilities-An empirical-test. Organization Science, 6: 76-92.

Zollo, M. 2009. Superstitious learning with rare strategic decisions: Theory and evidence from corporate acquisitions. Organization Science, 20: 894-908.

Zollo, M., Reuer, J. J., \& Singh, H. 2002. Interorganizational routines and performance in strategic alliances. Organization Science, 13: 701-713.

Zollo, M., \& Winter, S. G. 2002. Deliberate learning and the evolution of dynamic capabilities. Organization Science, 13: 339-351. 